\title{
Cardiovascular Disease Mortality and Cancer Incidence in Vegetarians: A Meta-Analysis and Systematic Review
}

\author{
Tao Huang ${ }^{a, b}$ Bin Yang ${ }^{a, b}$ Jusheng Zheng ${ }^{a, b}$ Guipu Li ${ }^{a, b} \quad$ Mark L. Wahlqvist ${ }^{a-c}$ \\ Duo $\mathrm{Li}^{\mathrm{a}} \mathrm{b}$ \\ a Department of Food Science and Nutrition, Zhejiang University, and ${ }^{\mathrm{b}}$ APCNS Centre of Nutrition and Food Safety, \\ Hangzhou, China; ' ${ }^{\mathrm{M}}$ Monash Asia Institute, Monash University, Melbourne, Vic., Australia
}

\section{Key Words}

Vegetarians $\cdot$ Mortality $\cdot$ Cancer $\cdot$ Incidence $\cdot$ Meta-analysis

\begin{abstract}
Background: Prospective cohort studies have examined mortality and overall cancer incidence among vegetarians, but the results have been inconclusive. Aims: The objective of the present meta-analysis was to investigate cardiovascular disease mortality and cancer incidence among vegetarians and nonvegetarians. Methods: Medline, EMBASE and Web Of Science databases were searched for cohort studies published from inception to September 2011. Studies were included if they contained the relative risk (RR) and corresponding $95 \% \mathrm{Cl}$. Participants were from the UK, Germany, California, USA, the Netherlands and Japan. Results: Seven studies with a total of 124,706 participants were included in this analysis. All-cause mortality in vegetarians was $9 \%$ lower than in nonvegetarians ( $\mathrm{RR}=0.91 ; 95 \% \mathrm{Cl}, 0.66-1.16)$. The mortality from ischemic heart disease was significantly lower in vegetarians than in nonvegetarians ( $\mathrm{RR}=0.71 ; 95 \% \mathrm{Cl}$, $0.56-0.87$ ). We observed a $16 \%$ lower mortality from circulatory diseases ( $\mathrm{RR}=0.84 ; 95 \% \mathrm{Cl}, 0.54-1.14)$ and a $12 \%$ lower mortality from cerebrovascular disease $(\mathrm{RR}=0.88 ; 95 \% \mathrm{Cl}$, 0.70-1.06) in vegetarians compared with nonvegetarians. Vegetarians had a significantly lower cancer incidence than
\end{abstract}

nonvegetarians ( $\mathrm{RR}=0.82 ; 95 \% \mathrm{Cl}, 0.67-0.97)$. Conclusions: Our results suggest that vegetarians have a significantly lower ischemic heart disease mortality (29\%) and overall cancer incidence (18\%) than nonvegetarians.

Copyright $\odot 2012$ S. Karger AG, Basel

\section{Introduction}

The number of vegetarians is increasing in many western countries [1]. Besides avoiding meat, vegetarians generally exhibit other healthy lifestyle habits such as abstinence from smoking and alcohol consumption [2]. Studies of risk factors for chronic disease have shown that vegetarians have lower serum cholesterol concentrations, lower body mass indices, lower incidence of diabetes and possibly lower blood pressure than comparable nonvegetarians $[1,3]$. A repeatedly asked question is whether the avoidance of meat or other dietary components plays an important role in reducing mortality. There is some evidence suggesting that meat consumption increases the risk of cancers of the colorectum, breast and prostate $[4,5]$. Particular dietary practices and lifestyles, therefore, have often provided instructive insight into the effect of diet and lifestyle factors on mortality from specific causes.

\section{KARGER \\ Fax +4161306 1234 E-Mail karger@karger.ch} www.karger.com

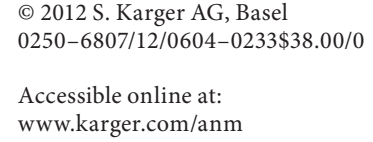

Tel. +86 5718697 1024,E-Mail duoli@zju.edu.cn 
Five prospective cohort studies involving a large proportion of vegetarians and nonvegetarians with a shared interest in healthy living or a similar social/religious background have reported some evidence that infrequent meat consumption or vegetarianism was associated with a reduction in mortality from ischemic heart disease, but some of these individual results were not statistically significant or were not observed in both sexes [2]. However, an association of vegetarian diets with a lower risk of coronary heart disease has been well established across studies $[3,6,7]$. In addition, meat consumption was associated with an increased mortality rate from prostate cancer, bladder cancer and ovarian cancer but not with mortality from cancers of the colorectum and breast [1]. Results from the Adventist Health Study have suggested that vegetarians have a significantly lower risk of cancers of the colon and prostate than nonvegetarians, but the risk of breast cancer does not differ significantly between these dietary groups [8]. Results from the Oxford Vegetarian Study suggested no large difference in the incidence of colorectal cancer between vegetarians and nonvegetarians [9], whereas the UK Women's Cohort Study suggested that women who do not eat any meat have a lower risk of breast cancer than do meat eaters [10]. A pooled analysis of mortality rates in 5 prospective studies suggested no large differences in overall cancer mortality between vegetarians and nonvegetarians [11].

Therefore, the associations of a vegetarian diet with mortality from specific causes are not firmly established, although it is most certain for disease-specific mortality from cardiovascular diseases $[12,13]$ and certain cancers [14]. The current analysis sought to analyze previous vegetarian cohort studies together using, as far as possible, common definitions in order to provide an overall estimate of any association of a vegetarian diet with mortality and cancer incidence.

\section{Methods}

\section{Data Sources and Study Selection}

We searched Medline, EMBASE and Web Of Science electronic databases from inception to September 2011for the following terms: 'vegetarians', 'nonvegetarians', 'omnivore', 'all-cause mortality', 'ischemic heart disease', 'circulatory diseases', 'cancer incidence', 'mortality', 'Adventist', 'Zen priest' and 'vegetarianism'. Study selection and data extraction were undertaken independently by two investigators with discrepancies resolved by consensus. The search was restricted to studies published in Englishlanguage journals. We included cohort studies that evaluated associations of vegetarians/nonvegetarians with all-cause mortality, disease-specific mortality of cardiovascular diseases and cancer incidence in humans. No restrictions were placed on the duration of follow-up or sample size. We excluded cross-sectional studies, letters and reviews. Studies were excluded from the pooled analysis if an outcome or data change was not obtainable.

\section{Data Extraction}

Data extraction was independently conducted by 2 authors (T.H. and B.Y.) blinded to the title, author and journal of publication. The data abstracted for each study were confirmed by reviewer consensus. The data that we collected included the first author's name, year of publication, duration of follow-up, number and age of participants, relative risk ratios (RRs) and standard errors (SEs) of these estimates, sample size, and cause of mortality. The study quality was assessed using the score method [15] in which the score ranged from 0 to 5 . Criteria for assessment of the study quality included the method of the study, sample size or objective measurements and duration of follow-up.

\section{Data Analyses and Statistical Methods}

Extracted data were analyzed using Stata version 11 software (StataCorp, College Station, Tex., USA). A random-effects model was used to pool data. Effect sizes are presented as RR with $95 \%$ CI. Heterogeneity was assessed using the $\chi^{2}$ method. Publication bias was assessed with the Egger test and the Begg-Mazumdar test $[16,17]$. Sensitivity analyses were planned a priori and undertaken for the following variables: study design, number of subjects, country and length of follow-up.

\section{Results}

\section{Study Selection}

Our comprehensive search identified 175 citations using our search approach. These citations were sequentially screened independently by 2 authors (T.H. and B.Y.) for inclusion. Twenty citations were reviewed using the full articles. Repeated reports were excluded [12, 18-22]. Seven cohort studies met the inclusion criteria for the systematic review $[2,13,18,23-26]$ (fig. 1).

The characteristics of the included studies are shown in table 1. Six of the cohort studies were conducted in European countries of dominant European ethnicity and one was undertaken in Japan among Zen Buddhist priests. The duration of the studies was from 10 to 23 years. The age of the participants ranged from 10 to 90 years. A total of 124,706 participants were included in the present meta-analysis. In these 7 studies, vegetarians included lacto-ovo vegetarians (who did not eat meat or fish or ate these foods less than once a week, but did eat eggs or dairy products, or both) or vegans (who did not eat meat, fish, eggs or dairy products).

\section{Data Synthesis}

Seven studies were included in the analysis of all-cause mortality $[2,13,18,23-26]$ (table 2). All-cause mortality 
Fig. 1. Flowchart for selection of included
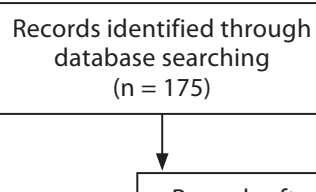

Records after duplicates removed

$(n=175)$

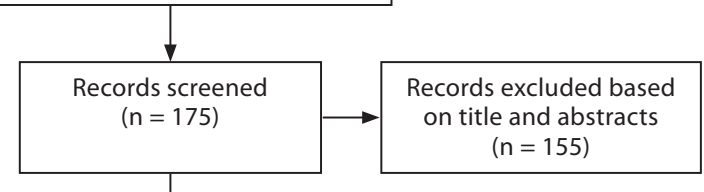

Full-text articles assessed for eligibility $(n=20)$

dditional records identified through other sources $(\mathrm{n}=0)$ cohort studies.

Table 1. Characteristics of the 7 included cohort studies

\begin{tabular}{|c|c|c|c|c|c|c|c|c|c|c|}
\hline Study & Study name & Country & $\begin{array}{l}\text { Median year } \\
\text { of recruitment }\end{array}$ & $\begin{array}{l}\text { End of } \\
\text { follow-up }\end{array}$ & $\begin{array}{l}\text { Follow- } \\
\text { up, years }\end{array}$ & $\begin{array}{l}\text { Number } \\
\text { of subjects }\end{array}$ & Adjusted covariables & $\begin{array}{l}\text { Age } \\
\text { years }\end{array}$ & $\begin{array}{l}\text { Cause of } \\
\text { mortality }\end{array}$ & $\begin{array}{l}\text { Study } \\
\text { quality }\end{array}$ \\
\hline $\begin{array}{l}\text { Beeson et al. } \\
{[18], 1989}\end{array}$ & $\begin{array}{l}\text { California } \\
\text { Seventh-Day } \\
\text { Adventists }\end{array}$ & $\begin{array}{l}\text { California, } \\
\text { USA }\end{array}$ & $\begin{array}{l}1976 \\
(1976-1980)\end{array}$ & 1988 & 11.1 & 28,952 & $\begin{array}{l}\text { BMI, alcohol intake, } \\
\text { education and } \\
\text { exercise }\end{array}$ & $20-89$ & $\begin{array}{l}\text { All causes } \\
\text { of death }\end{array}$ & 3 \\
\hline $\begin{array}{l}\text { Berkel and de } \\
\text { Waard [24], } \\
1983\end{array}$ & $\begin{array}{l}\text { Seventh-Day } \\
\text { Adventists in } \\
\text { the Netherlands }\end{array}$ & $\begin{array}{l}\text { The } \\
\text { Nether- } \\
\text { lands }\end{array}$ & $\begin{array}{l}1968 \\
(1968-1977)\end{array}$ & 1977 & 10 & 3,217 & $\begin{array}{l}\text { BMI, alcohol intake, } \\
\text { education and } \\
\text { exercise }\end{array}$ & $20-89$ & $\begin{array}{l}\text { All causes } \\
\text { of death }\end{array}$ & 2 \\
\hline $\begin{array}{l}\text { Chang-Claude } \\
\text { et al. [2], } 2005\end{array}$ & $\begin{array}{l}\text { The Heidelberg } \\
\text { Study }\end{array}$ & Germany & $\begin{array}{l}1976 \\
(1976-1978)\end{array}$ & 1999 & 21 & 1,904 & $\begin{array}{l}\text { Age, sex, smoking, } \\
\text { alcohol intake, BMI, } \\
\text { education and } \\
\text { activity level }\end{array}$ & $>10$ & $\begin{array}{l}\text { All causes } \\
\text { of death }\end{array}$ & 4 \\
\hline $\begin{array}{l}\text { Key et al. [26], } \\
1996\end{array}$ & $\begin{array}{l}\text { Health Food } \\
\text { Shoppers }\end{array}$ & UK & $\begin{array}{l}1973 \\
(1973-1979)\end{array}$ & 1995 & 17 & 11,000 & $\begin{array}{l}\text { Age, sex, smoking, } \\
\text { alcohol intake, BMI } \\
\text { and education }\end{array}$ & $16-89$ & $\begin{array}{l}\text { All causes } \\
\text { of death }\end{array}$ & 5 \\
\hline $\begin{array}{l}\text { Key et al. [13], } \\
2009\end{array}$ & $\begin{array}{l}\text { The EPIC-Oxford } \\
\text { cohort }\end{array}$ & UK & $\begin{array}{l}1993 \\
(1993-1999)\end{array}$ & 2007 & 17 & 64,234 & $\begin{array}{l}\text { Age, sex, smoking } \\
\text { and alcohol } \\
\text { consumption }\end{array}$ & $20-89$ & $\begin{array}{l}\text { All causes } \\
\text { of death }\end{array}$ & 5 \\
\hline $\begin{array}{l}\text { Ogata et al. } \\
{[25], 1984}\end{array}$ & $\begin{array}{l}\text { Japanese male } \\
\text { Zen priests study }\end{array}$ & Japan & $1955-1978$ & 1978 & 23 & 4,352 & $\begin{array}{l}\text { BMI, alcohol intake, } \\
\text { education and } \\
\text { exercise }\end{array}$ & $>20$ & $\begin{array}{l}\text { All causes } \\
\text { of death }\end{array}$ & 1 \\
\hline $\begin{array}{l}\text { Thorogood et } \\
\text { al. [23], } 1994\end{array}$ & $\begin{array}{l}\text { Oxford } \\
\text { Vegetarian Study }\end{array}$ & UK & $\begin{array}{l}1981 \\
(1980-1984)\end{array}$ & 1995 & 13.7 & 11,047 & $\begin{array}{l}\text { Smoking, BMI and } \\
\text { social class }\end{array}$ & $20-89$ & $\begin{array}{l}\text { All causes } \\
\text { of death }\end{array}$ & 4 \\
\hline
\end{tabular}


Table 2. All-cause mortality in vegetarians and nonvegetarians

\begin{tabular}{|c|c|c|c|c|}
\hline \multirow[t]{2}{*}{ Study } & \multicolumn{2}{|c|}{ Vegetarians } & \multicolumn{2}{|c|}{ Nonvegetarians } \\
\hline & event & total & event & total \\
\hline \multicolumn{5}{|l|}{ Chang-Claude et al. [2], } \\
\hline 2005 & 380 & 1,225 & 155 & 679 \\
\hline Key et al. [13], 2009 & 654 & 16,081 & 2,311 & 31,173 \\
\hline Beeson et al. [18], 1989 & 3,564 & 8,003 & 10,480 & 20,949 \\
\hline \multicolumn{5}{|l|}{ Thorogood et al. [23], } \\
\hline 1994 & 819 & 4,674 & 1,119 & 6,373 \\
\hline \multicolumn{5}{|l|}{ Berkel and deWaard [24], } \\
\hline 1983 & 1,104 & 4,000 & \multirow{2}{*}{\multicolumn{2}{|c|}{$\begin{array}{l}\text { Dutch population } \\
\text { General Japanese } \\
\text { male population }\end{array}$}} \\
\hline Ogata et al. [25], 1984 & 1,396 & 4,352 & & \\
\hline Key et al. [26], 1996 & 1,343 & 11,000 & 2,686 & 11,000 \\
\hline
\end{tabular}

was $9 \%$ lower in vegetarians than in nonvegetarians after the follow-up. The RR and 95\% CI for all-cause mortality are shown in figure 2. The pooled RR is 0.91 (95\% CI, $0.66-1.16$ ).

Six studies were included in the analysis of ischemic heart disease mortality $[2,13,18,23,24,26]$. We found that ischemic heart disease mortality was significantly lower (by 29\%) in vegetarians than in nonvegetarians ( $\mathrm{RR}=0.71 ; 95 \% \mathrm{CI}, 0.56-0.87)$ (fig. 3). We further analyzed the circulatory diseases (ischemic heart disease and cerebrovascular disease) in vegetarians and nonvegetarians. Five studies were included in this analysis $[2,13,23$, $24,26]$. The circulatory disease mortality was $16 \%$ lower in vegetarians than in nonvegetarians $(\mathrm{RR}=0.84 ; 95 \%$

\begin{tabular}{|c|c|c|c|}
\hline $\begin{array}{l}\text { All-cause mortality } \\
\text { ID }\end{array}$ & & $\mathrm{ES}(95 \% \mathrm{Cl})$ & $\begin{array}{l}\text { Weight } \\
\%\end{array}$ \\
\hline Key et al. [13], 2009 & - & $1.05(0.93,1.19)$ & 14.05 \\
\hline Beeson et al. [18], 1989 & $-\infty-1$ & $0.80(0.74,0.87)$ & 14.46 \\
\hline Chang-Claude et al. [2], 2005 & $\rightarrow-$ & $1.19(1.13,1.27)$ & 14.43 \\
\hline Thorogood et al. [23], 1994 & & $1.01(0.89,1.14)$ & 14.09 \\
\hline Berkel and de Waard [24], 1983 & $\rightarrow$ & $0.45(0.41,0.49)$ & 14.54 \\
\hline Ogata et al. [25], 1984 & -1 & $0.82(0.72,0.92)$ & 14.27 \\
\hline Key et al. [26], 1996 & & $1.04(0.93,1.16)$ & 14.16 \\
\hline Overall $\left(I^{2}=28.6 \%, p=0.089\right)$ & & $0.91(0.66,1.16)$ & 100.00 \\
\hline \multicolumn{4}{|l|}{ Note: weights are from random effects analysis } \\
\hline 0 & 1 & & \\
\hline
\end{tabular}

Fig. 2. Forest plot summary of all-cause mortality in 7 studies included in the meta-analysis. ID = Author name and year; ES = effect size.

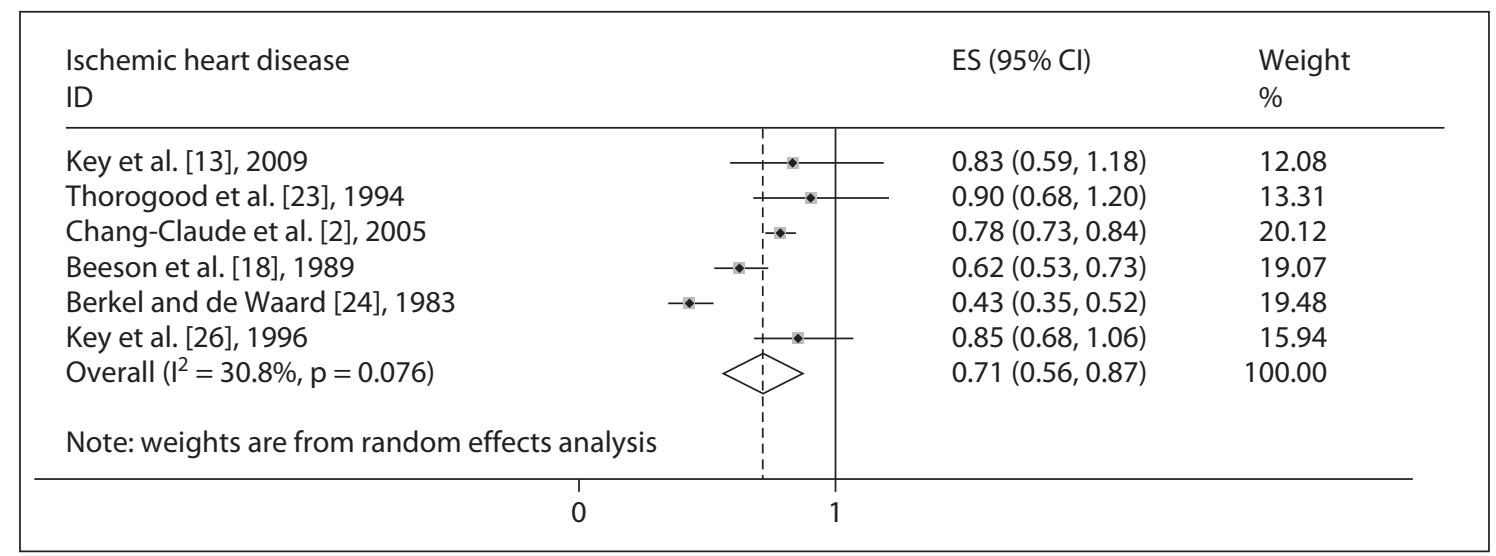

Fig. 3. Forest plot summary of ischemic heart disease mortality in 6 studies included in the meta-analysis. $\mathrm{ID}=$ Author name and year; ES = effect size. 
CI, 0.54-1.14) with significant heterogeneity $\left(\mathrm{I}^{2}=58 \%\right.$, $\mathrm{p}=0.046$ ) (fig. 4). In sensitivity analyses, we excluded the studies one by one to identify the source of heterogeneity. It was noted that when the study by Berkel and de Waard [24] was excluded no heterogeneity was observed $\left(\mathrm{I}^{2}=\right.$ $0 \%, \mathrm{p}=0.986)$. However, no significant changes in the circulatory disease mortality were observed $(\mathrm{RR}=0.91$; $95 \%$ CI, $0.74-1.01$ ). We also noted a $12 \%$ lower cerebrovascular disease rate in vegetarians than in nonvegetarians ( $\mathrm{RR}=0.88$; 95\% CI, 0.70-1.06) (fig. 5).

Seven studies were included in the further analysis of the cancer incidence among vegetarians and nonvegetarians $[2,9,18,24-28]$. We found an $18 \%$ lower cancer incidence in vegetarians than in nonvegetarians. The RR and 95\% CI for cancer incidence are shown in figure 6. The pooled RR is 0.82 (95\% CI, 0.67-0.97).

Begg's funnel plot and Begg's test showed a slight significant publication bias in all-cause mortality, cancer incidence, ischemic heart disease and circulatory disease. No publication bias was observed in cerebrovascular disease.

\section{Discussion}

In the present study we sought to extend these observations by combining the studies of vegetarians to give reasonable scope for detecting associations with mortal-

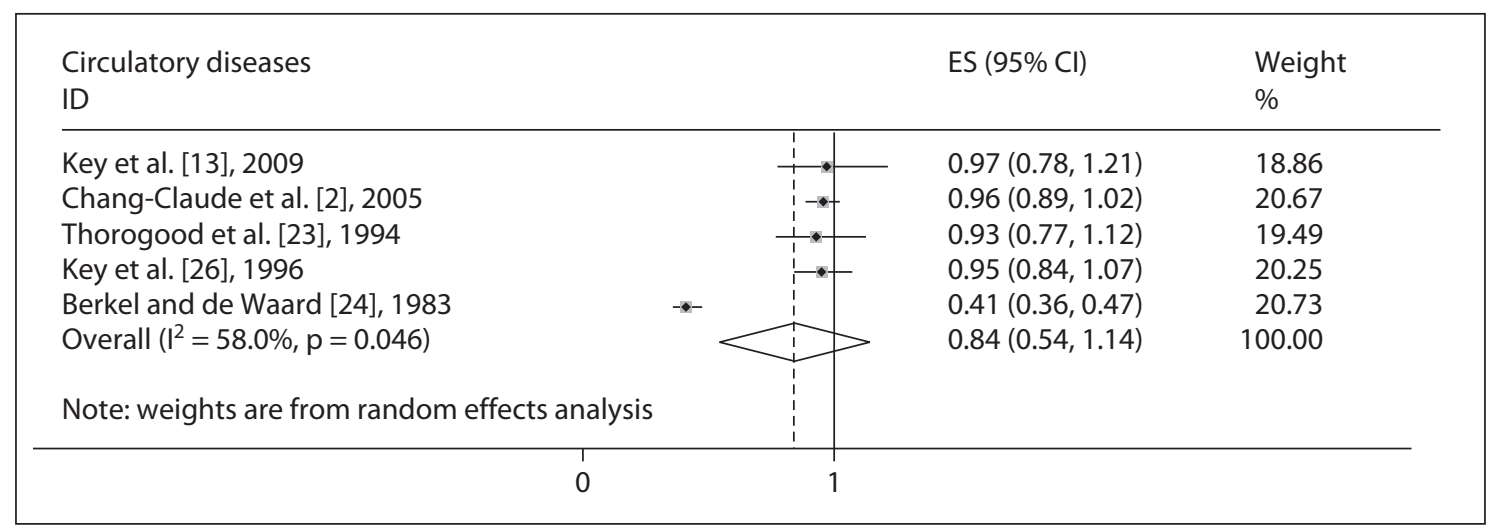

Fig. 4. Forest plot summary of circulatory disease mortality in 5 studies included in the meta-analysis. ID = Author name and year; ES = effect size.

\begin{tabular}{|c|c|c|c|}
\hline $\begin{array}{l}\text { Cerebrovascular disease } \\
\text { ID }\end{array}$ & & $\mathrm{ES}(95 \% \mathrm{Cl})$ & $\begin{array}{l}\text { Weight } \\
\%\end{array}$ \\
\hline Key et al. [13], 2009 & & $1.10(0.77,1.58)$ & 10.04 \\
\hline Thorogood et al. [23], 1994 & + & $1.17(0.76,1.80)$ & 7.58 \\
\hline Chang-Claude et al. [2], 2005 & & $0.98(0.86,1.14)$ & 17.96 \\
\hline Beeson et al. [18], 1989 & $\rightarrow$ & $0.93(0.71,1.02)$ & 17.55 \\
\hline Berkel and de Waard [24], 1983 & $\begin{array}{rr}1 \\
-\quad 1\end{array}$ & $0.54(0.43,0.67)$ & 18.48 \\
\hline Ogata et al. [25], 1984 & 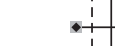 & $0.78(0.76,1.15)$ & 16.32 \\
\hline Key et al. [26], 1996 & & $0.96(0.69,1.35)$ & 12.07 \\
\hline Overall $\left(I^{2}=31.3 \%, p=0.067\right)$ & 1 & $0.88(0.70,1.06)$ & 100.00 \\
\hline \multicolumn{4}{|l|}{ Note: weights are from random effects analysis } \\
\hline 0 & 1 & & \\
\hline
\end{tabular}

Fig. 5. Forest plot summary of cerebrovascular disease mortality in 7 studies included in the meta-analysis. $\mathrm{ID}=$ Author name and year; ES = effect size. 


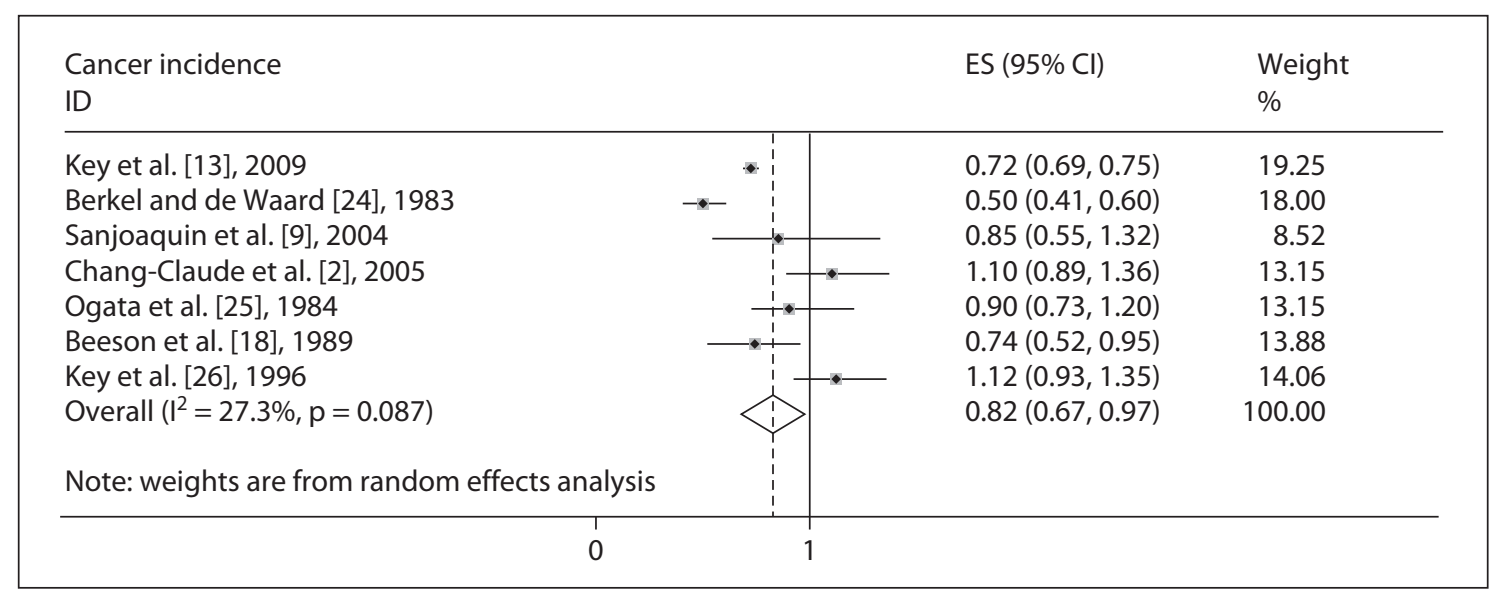

Fig. 6. Forest plot summary of cancer incidence in 7 studies included in the meta-analysis. ID = Author name and year; $\mathrm{ES}=$ effect size.

ity from all-cause mortality and cancer incidence. We believe that the studies analyzed here are the only prospective studies that included a large number of subjects. Therefore, the results presented here represent most of the information available on comparisons of mortality between vegetarians and nonvegetarians with broadly similar lifestyles. The exception in the present meta-analysis is the inclusion of the Japanese Zen Buddhist study where the principles of vegetarianism are somewhat different to those encountered among those of European ancestry.

The overall cancer incidence rates and mortality from ischemic heart disease were significantly lower in vegetarians than in nonvegetarians, and all-cause mortality and mortality from circulatory disease were 9 and 16\% lower in vegetarians than in nonvegetarians.

We observed a 9\% lower all-cause mortality in vegetarians than in nonvegetarians. Our results are consistent with previous studies $[13,29]$. In the EPIC-Oxford study, for all causes of death combined, the rate of mortality in vegetarians was similar to that in meat eaters, and the rate of mortality in fish eaters was nonsignificantly lower than in meat eaters [13]. Moreover, in the previous collaborative analysis of 5 prospective studies, the rate of all-cause mortality was nonsignificantly lower among vegetarians than among nonvegetarians [11]. However, data from a prospective cohort study of adults in North America and Europe raise the possibility that a lifestyle pattern that includes a very low meat intake is associated with greater longevity [30]. In the subgroup analysis we found that ischemic heart disease mortality was $22 \%$ lower in vegetarians than in nonvegetarians. Previous studies also re- ported similar results [31-34]. In addition, mortality from ischemic heart disease was $24 \%$ (95\% CI: 0.06, 0.38) lower among vegetarians than among nonvegetarians in the collaborative reanalysis of 5 prospective studies [11]. The lower mortality from ischemic heart disease among vegetarians was greater in those of a younger age and was restricted to those who had followed their current diet for more than 5 years [11]. The highly significant association suggests that the lower mortality from ischemic heart disease was due to the dietary differences between vegetarians and nonvegetarians. The relatively low prevalence of smoking in these cohorts [11] and the lower serum total cholesterol concentrations in vegetarians also contributed to the lower mortality from ischemic heart disease among the vegetarians [35-37]. Other factors such as reduced oxidation of LDL cholesterol or changes in blood clotting also help explain the lower mortality rate in vegetarians [11].

Moreover, mortality from circulatory diseases (ischemic heart disease and cerebrovascular disease) in the present study is $16 \%$ lower in vegetarians than in nonvegetarians. The possible reason for this result is that there were no significant differences between vegetarians and nonvegetarians in mortality from cerebrovascular disease which is one component of circulatory diseases [1, 11]. High-fat diets are implicated in the onset of cardiovascular disease, cancer and obesity. Large intakes of saturated and trans-fatty acids, therefore, together with low levels of polyunsaturated fatty acids, particularly n-3 polyunsaturated fatty acids, appear to have the greatest impact on the development of cardiovascular disease [38]. Hence, lower platelet/plasma concentrations of $n-3$ 
polyunsaturated fatty acids in vegetarians may contribute to the nonsignificant difference in mortality from circulatory diseases in these two groups [39-40]. We also thought that the marginal association of mortality rate with vegetarians might have been due to residual confounding among former smokers or to a recent change in diet in an attempt to alleviate ill health. For example, smoking and both low and high BMI increased mortality, and moderate alcohol consumption decreased mortality from circulatory diseases, ischemic heart disease, and all causes combined $[13,41]$.

We found that the overall cancer incidence in vegetarians was $18 \%$ lower than in nonvegetarians. This reduction in risk associated with vegetarianism might be due to changes in diet during the long-term follow-up of the study. Some large studies have found a significant correlation between red meat consumption and the incidence of colon cancer [42], but large prospective studies do not confirm this observation $[11,27,43,44]$. The difference in total cancer between meat eaters and nonmeat eaters could not be ascribed to any one of the major cancer sites examined. This difference might be partly due to dietary differences between the groups. Furthermore, the results may be influenced by residual confounding because of measurement error in the assessment of confounding factors and by confounding by unknown factors. However, among vegetarians who had followed their current diet for less than 5 years, mortality was significantly higher than in nonvegetarians from lung cancer, other causes, and all causes [11]. The cause of this small difference is not known. More data are needed to further our understanding of this observation which, if confirmed, is likely to be due to differences for specific cancer sites.

Our study is the first meta-analysis to date which has pooled all the data available to investigate the associations between vegetarians and all-cause mortality and cancer incidence. We, therefore, included more cohort studies than any previous relevant studies and provided more sufficient data for this issue. Some limitations are also presented here. First, cohort studies could not avoid the residual confounding or bias despite their relatively longer duration period and larger sample size. Second, we have pooled the data from different ethnicities together, leading to some unavoidable bias. Finally, exclusion of studies which did not provide adequate information might contribute to the tested publication bias.

A potential weakness of the type of cohort studies we have compiled is the accuracy of the assessment of vegetarian status $[27,45]$. Vegetarian diets can differ in many ways from nonvegetarian diets, and vegetarian diets themselves vary between different vegetarian groups as in the case of Buddhist vegetarianism [1]. In comparison to the mortality from all-cause mortality among vegetarians, there was also heterogeneity between studies. Moreover, the vegetarians were compared with all nonvegetarians or with meat eaters. Some heterogeneity between studies is to be expected because the dietary differences between vegetarians and nonvegetarians vary between different populations, but we did not have sufficient dietary data from these studies to evaluate this fully. Therefore, it is impossible to draw any conclusions as to which aspects of the diet are protective [1].

In conclusion, the overall cancer incidence and mortality from ischemic heart disease were significantly lower, but there were no associations of a vegetarian diet with all-cause mortality and mortality from circulatory and cerebrovascular diseases.

\section{Acknowledgements}

This work was supported by grants from the National High Technology Research and Development Program of China (No. N20080753), the National Natural Science Foundation of China (No. 30972464) and the PhD Programs Foundation of the Ministry of Education of China (No. 20070335025).

\section{Disclosure Statement}

The authors have no conflicts of interest to disclose.

\section{References}

-1 Key TJ, Fraser GE, Thorogood M, et al: Mortality in vegetarians and non-vegetarians: a collaborative analysis of 8,300 deaths among 76,000 men and women in five prospective studies. Public Health Nutr 1998;1:33-41.

2 Chang-Claude J, Hermann S, Eilber U, et al: Lifestyle determinants and mortality in German vegetarians and health-conscious per- sons: results of a 21-year follow-up. Cancer Epidemiol Biomarkers Prev 2005; 14:963-968.

3 Fraser GE: Vegetarian diets: what do we know of their effects on common chronic diseases? Am J Clin Nutr 2009;89:1607S$1612 S$.

-4 Giovannucci E, Rimm EB, Stampfer MJ, et al: Intake of fat, meat, and fiber in relation to risk of colon-cancer in men. Cancer Res 1994;54:2390-2397.

5 Bingham SA: High-meat diets and cancer risk. Proc Nutr Soc 1999;58:243-248.

6 Fisher M, Levine PH, Weiner B, et al: The effect of vegetarian diets on plasma-lipid and platelet levels. Arch Intern Med 1986;146: 1193-1197. 
7 Phillips RL, Lemon FR, Beeson WL, et al: Coronary heart disease mortality among Seventh-Day Adventists with differing dietary habits: a preliminary report. Am J Clin Nutr 1978;31:S191-S198.

$\checkmark 8$ Fraser GE: Associations between diet and cancer, ischemic heart disease, and all-cause mortality in non-Hispanic white California Seventh-day Adventists. Am J Clin Nutr 1999;70(suppl 3):532S-538S.

$\checkmark 9$ Sanjoaquin MA, Appleby PN, Thorogood M, et al: Nutrition, lifestyle and colorectal cancer incidence: a prospective investigation of 10,998 vegetarians and non-vegetarians in the United Kingdom. Br J Cancer 2004;90: 118-121.

10 Roddam AW, Pirie K, Pike MC, et al: Active and passive smoking and the risk of breast cancer in women aged $36-45$ years: a population based case-control study in the UK. Br J Cancer 2007;97:434-439.

-11 Key TJ, Fraser GE, Thorogood M, et al: Mortality in vegetarians and nonvegetarians: detailed findings from a collaborative analysis of 5 prospective studies. Am J Clin Nutr 1999;70(3 suppl):516S-524S

$\checkmark 12$ Appleby PN, Key TJ, Thorogood M, et al: Mortality in British vegetarians. Public Health Nutr 2002;5:29-36.

$\checkmark 13$ Key TJ, Appleby PN, Spencer EA, et al: Mortality in British vegetarians: results from the European Prospective Investigation into Cancer and Nutrition (EPIC-Oxford). Am J Clin Nutr 2009;89:1613S-1619S.

$\checkmark 14$ Kushi LH, Byers T, Doyle C, et al: American Cancer Society guidelines on nutrition and physical activity for cancer prevention: reducing the risk of cancer with healthy food choices and physical activity. CA Cancer J Clin 2006;56:254-281.

15 Jadad AR, Moore RA, Carroll D, et al: Assessing the quality of reports of randomized clinical trials: is blinding necessary? Control Clin Trials 1996;17:1-12.

-16 Egger M, Davey Smith G, Schneider M, et al: Bias in meta-analysis detected by a simple, graphical test. BMJ 1997;315:629-634.

$\checkmark 17$ Begg CB, Mazumdar M: Operating characteristics of a rank correlation test for publication bias. Biometrics 1994;50:1088-1101.

18 Beeson WL, Mills PK, Phillips RL, et al: Chronic disease among Seventh-day Adventists, a low-risk group - rationale, methodology, and description of the population. Cancer $1989 ; 64: 570-581$.
19 Snowdon DA: Animal product consumption and mortality because of all causes combined, coronary heart disease, stroke, diabetes, and cancer in Seventh-day Adventists. Am J Clin Nutr 1988;48(suppl 3):739-748.

20 Phillips RL, Garfinkel L, Kuzma JW, et al: Mortality among California Seventh-Day Adventists for selected cancer sites. J Natl Cancer Inst 1980;65:1097-1107.

21 Burr ML, Sweetnam PM: Vegetarianism, dietary fiber, and mortality. Am J Clin Nutr 1982;36:873-877.

22 Frentzel-Beyme R, Claude J, Eilber U: Mortality among German vegetarians: first results after 5 years of follow-up. Nutr Cancer 1988;11:117-126.

23 Thorogood M, Mann J, Appleby P, et al: Risk of death from cancer and ischaemic heart disease in meat and non-meat eaters. BM] 1994;308:1667-1670.

24 Berkel J, de Waard F: Mortality pattern and life expectancy of Seventh-Day Adventists in the Netherlands. Int J Epidemiol 1983;12: 455-459.

25 Ogata M, Ikeda M, Kuratsune M: Mortality among Japanese Zen priests. J Epidemiol Community Health 1984;38:161-166.

26 Key TJ, Thorogood M, Appleby PN, et al: Dietary habits and mortality in 11,000 vegetarians and health conscious people: results of a 17 year follow up. BMJ 1996;313:775-779.

$>27$ Key TJ, Appleby PN, Spencer EA, et al: Cancer incidence in vegetarians: results from the European Prospective Investigation into Cancer and Nutrition (EPIC-Oxford). Am J Clin Nutr 2009;89:1620S-1626S.

28 Mills PK, Beeson WL, Phillips RL, et al: Cancer incidence among California SeventhDay Adventists, 1976-1982. Am J Clin Nutr 1994;59(suppl 5):1136S-1142S.

29 Key TJ, Appleby PN, Davey GK, et al: Mortality in British vegetarians: review and preliminary results from EPIC-Oxford. Am J Clin Nutr 2003;78(suppl 3):533S-538S.

30 Singh PN, Sabate J, Fraser GE: Does low meat consumption increase life expectancy in humans? Am J Clin Nutr 2003;78:526S-532S.

31 Snowdon DA, Phillips RL, Fraser GE: Meat consumption and fatal ischemic heart disease. Prev Med 1984;13:490-500.
32 Fraser GE, Sabate J, Beeson WL, et al: A possible protective effect of nut consumption on risk of coronary heart disease. The Adventist Health Study. Arch Intern Med 1992;152: 1416-1424.

33 Burr ML, Butland BK: Heart disease in British vegetarians. Am J Clin Nutr 1988;48(suppl 3):830-832.

>34 Chang-Claude J, Frentzel-Beyme R, Eilber $\mathrm{U}$ : Mortality pattern of German vegetarians after 11 years of follow-up. Epidemiology 1992;3:395-401.

35 Burr ML, Bates CJ, Fehily AM, et al: Plasma cholesterol and blood pressure in vegetarians. J Hum Nutr 1981;35:437-441.

-36 Thorogood M, Carter R, Benfield L, et al: Plasma lipids and lipoprotein cholesterol concentrations in people with different diets in Britain. Br Med J (Clin Res Ed) 1987;295: 351-353.

37 Law MR, Wald NJ, Wu T, et al: Systematic underestimation of association between serum cholesterol concentration and ischaemic heart disease in observational studies: data from the BUPA study. BMJ 1994;308: 363-366

38 Mann N, Pirotta Y, O’Connell S, et al: Fatty acid composition of habitual omnivore and vegetarian diets. Lipids 2006;41:637-646.

39 Li D, Sinclair A, Wilson A, et al: Effect of dietary alpha-linolenic acid on thrombotic risk factors in vegetarian men. Am J Clin Nutr 1999;69:872-882.

40 Li D: Chemistry behind vegetarianism. J Agric Food Chem 2011;59:777-784.

41 Ezzati M, Lopez AD, Rodgers A, et al: Selected major risk factors and global and regional burden of disease. Lancet 2002;360:13471360 .

42 Giovannucci E, Rimm EB, Stampfer MJ, et al: Intake of fat, meat, and fiber in relation to risk of colon cancer in men. Cancer Res 1994; 54:2390-2397.

-43 Thun MJ, Calle EE, Namboodiri MM, et al: Risk factors for fatal colon cancer in a large prospective study. J Natl Cancer Inst 1992; 84:1491-1500.

44 Kinlen LJ: Meat and fat consumption and cancer mortality: a study of strict religious orders in Britain. Lancet 1982;1:946-949.

$>45$ Key T, Davey G: Prevalence of obesity is low in people who do not eat meat. BMJ 1996;313: 816-817. 